\title{
Análise da Estrutura Fundiária do Município de Montes Claros-MG por Meio dos Dados do Cadastro Ambiental Rural (CAR)
}

\author{
Analysis of Land Structure Using Data from the \\ Rural Environmental Registry of Montes Claros \\ Municipality-Minas Gerais State
}

\author{
Bruno Alves Nobre \\ Universidade Estadual de Montes Claros \\ Montes Claros, Brasil \\ Marcos Esdras Leite \\ Universidade Estadual de Montes Claros \\ Montes Claros, Brasil \\ Samuel Carlos Santos Marquesiii \\ Universidade Estadual de Montes Claros \\ Montes Claros, Brasil
}

\begin{abstract}
Resumo: O Cadastro Ambiental Rural (CAR) é um registro público eletrônico georreferenciado de âmbito nacional, obrigatório para todos os imóveis rurais. O CAR, enquanto banco de dados georrefenciados, torna-se um instrumento de monitoramento da estrutura fundiária rural. Portanto, a análise de seus dados em ambiente SIG, cruzados com dados provenientes do sensoriamento remoto, permite melhor compreensão da realidade de uso da terra. Nesse contexto, este trabalho analisou a estrutura fundiária rural de Montes Claros. Para isso, em ambiente do Sistema de Informação Geográfica (SIG), foram cruzados os dados do CAR com informações extraídas de imagens de satélite. Os resultados mostram que a estrutura fundiária ainda está moldada no processo de exclusão social.
\end{abstract}

Palavras-chave: Cadastro Ambiental Rural; Pastagem; Estrutura Fundiária.

\begin{abstract}
The Rural Environmental Registry is a national geo-referenced electronic public registry, which is mandatory for all rural properties. As a geo-referenced database the Registry is an instrument for monitoring rural land structure in which the analysis

\footnotetext{
Mestrando no Programa de Pós-Graduação em Geografia. bruno.nobre13@gmail.com. https://orcid.org/0000-0002-5504-7194

ii Professor do Departamento de Geociências e do Programa de Pós-Graduação em Geografia. marcos.leite@unimontes.br. https://orcid.org/0000-0002-9020-6445

iii Graduando em Geografia. samuel35marques@gmail.com. https://orcid.org/0000-0002-02963164
} 
of its data in a GIS environment can be crossed with data from remote sensing so producing a better understanding of the reality of land use. This work analyzes rural land structure in Montes Claros municipality (Minas Gerais) by undertaking a GIS analysis of the Rural Environmental Registry data crossed with information extracted from satellite images. The results show that the land structure is still shaped by a process of social exclusion.

Keywords: Rural Environmental Registry; Pasture; Agrarian structure.

\section{Introdução}

Com a formação inicial das propriedades privadas no Brasil vieram os problemas decorrentes da concentração fundiária. Desde o Brasil colônia as terras foram distribuídas de maneira desigual, com evidente privilégio da posse às elites e disparidades na formação territorial do país.

É possível, então, pontuar que a terra no Brasil sempre foi ocupada de maneira a favorecer os grandes detentores de renda em detrimento ao interesse social das demais camadas da sociedade. A Lei de Terras de 1850, apenas reforçou esse cenário, trazendo a mercantilização da propriedade fundiária e a entrada do capitalismo na lógica agrária. (CAMACHO, 2011).

A agricultura brasileira sempre obedeceu à concepção capitalista. A concentração fundiária existente desde a chegada dos portugueses, que utilizavam as terras em benefício de uma minoria, o que, inclusive, acabou por intensificar a intransigência das elites pela ocupação e produção agrícola familiar.

A utilização do solo para a produção agrícola obedece a uma orientação mercadológica imposta pelo capital, o que repercute na própria organização da estrutura fundiária. As próprias variações de declividade e qualidade do solo para produção interferem no valor da terra e pautam a organização fundiária e a produção agrícola.

Com isso em vista, para uma melhor gestão das questões fundiárias, Loch (1988) afirma que é necessário um planejamento que comece a nível municipal, já que esta é a menor unidade administrativa prevista na legislação brasileira. E, para esse planejamento, todas as propriedades existentes devem ser registradas e mapeadas, para que se obtenha amplo e real conhecimento das características e detalhes da estrutura fundiária nacional.

A melhor possibilidade para produção de tal mapeamento é a utilização do Cadastro Ambiental Rural (CAR), que nada mais é que um registro público eletrônico georreferenciado de âmbito nacional, obrigatório para todos os imóveis rurais. É uma ferramenta informativa, que permite controle e monitoramento, integrando informações ambientais.

O Cadastro Ambiental Rural (CAR) é fruto do Decreto Federal no 7.029, de 10 de dezembro de 2009, com o propósito de estimular a regularização ambiental dos imóveis rurais. O CAR se consolidou como um instrumento de regularização ambiental dos imóveis rurais em âmbito nacional com a criação do Programa Federal de Apoio à 
Regularização Ambiental - Programa Mais Ambiente (PMA). O decreto definiu como instrumentos para regularização ambiental o CAR e o Termo de Adesão e Compromisso, pelo qual o agricultor assumia o compromisso de recuperar, recompor ou manter as Áreas de Proteção Ambiental (APPs), bem como de averbar a reserva legal do imóvel. (BRASIL, 2009).

Essa situação presente em todo o Brasil pode ser ilustrada pela realidade do município de Montes Claros/MG, que possui o maior PIB e a maior população do Norte, Nordeste e Noroeste de Minas Gerais. Apesar de o setor primário ter participação modesta no PIB, a pecuária é a principal atividade agrícola deste setor da economia.

Diante do que foi exposto, este trabalho é norteado pelas questões de pesquisa: Como é a estrutura fundiária no município de Montes Claros? A pecuária e a pastagem predominam em que tipo de propriedade?

A partir desses questionamentos, este trabalho objetiva, de maneira geral, analisar o uso da pastagem por tamanho da propriedade rural no município de Montes Claros/MG. Especificamente, objetiva, ainda, analisar a concentração e a fragmentação fundiária, além de analisar o tipo do relevo por tamanho das propriedades rurais.

A relevância deste trabalho justifica-se pelo norteamento a políticas públicas, pois se torna uma possibilidade de avançar analiticamente no monitoramento da distribuição das pastagens e dos conflitos fundiários e ambientais, o mapeamento da estrutura fundiária e da pastagem pode ser utilizado como indicadores sociais, principalmente no tocante ao planejamento socioambiental. Em Montes Claros/MG, o uso desse mapeamento se destaca, haja vista a importância da pecuária para a formação do município.

\section{Caracterização da Área}

A área de estudo corresponde ao município de Montes Claros (Figura 1), situa-se no

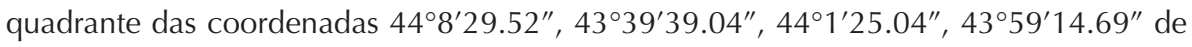
Longitude Oeste e $16^{\circ} 4^{\prime} 13.83^{\prime \prime}, 16^{\circ} 8^{\prime} 8.32^{\prime \prime}, 17^{\circ} 4^{\prime} 48.66^{\prime \prime}, 17^{\circ} 8^{\prime} 31.84^{\prime \prime}$ de Latitude Sul no Norte do estado de Minas Gerais (Figura 1), com altitude mínima de 498 m e máxima de 1092 m, o município tem uma área total de 3.576,76 km² (IBGE, 2010).

O clima é do tipo subúmido úmido, com período de chuvas concentradas entre os meses de outubro e março com precipitação média anual de 1.082,4 mm. O relevo varia de plano a forte ondulado. A cobertura vegetal do município é classificada como Cerrado conforme aponta o IBGE (2010), contendo variantes da Floresta Estacional Decidual e Floresta Estacional Semidecidual (LEITE, 2012). 


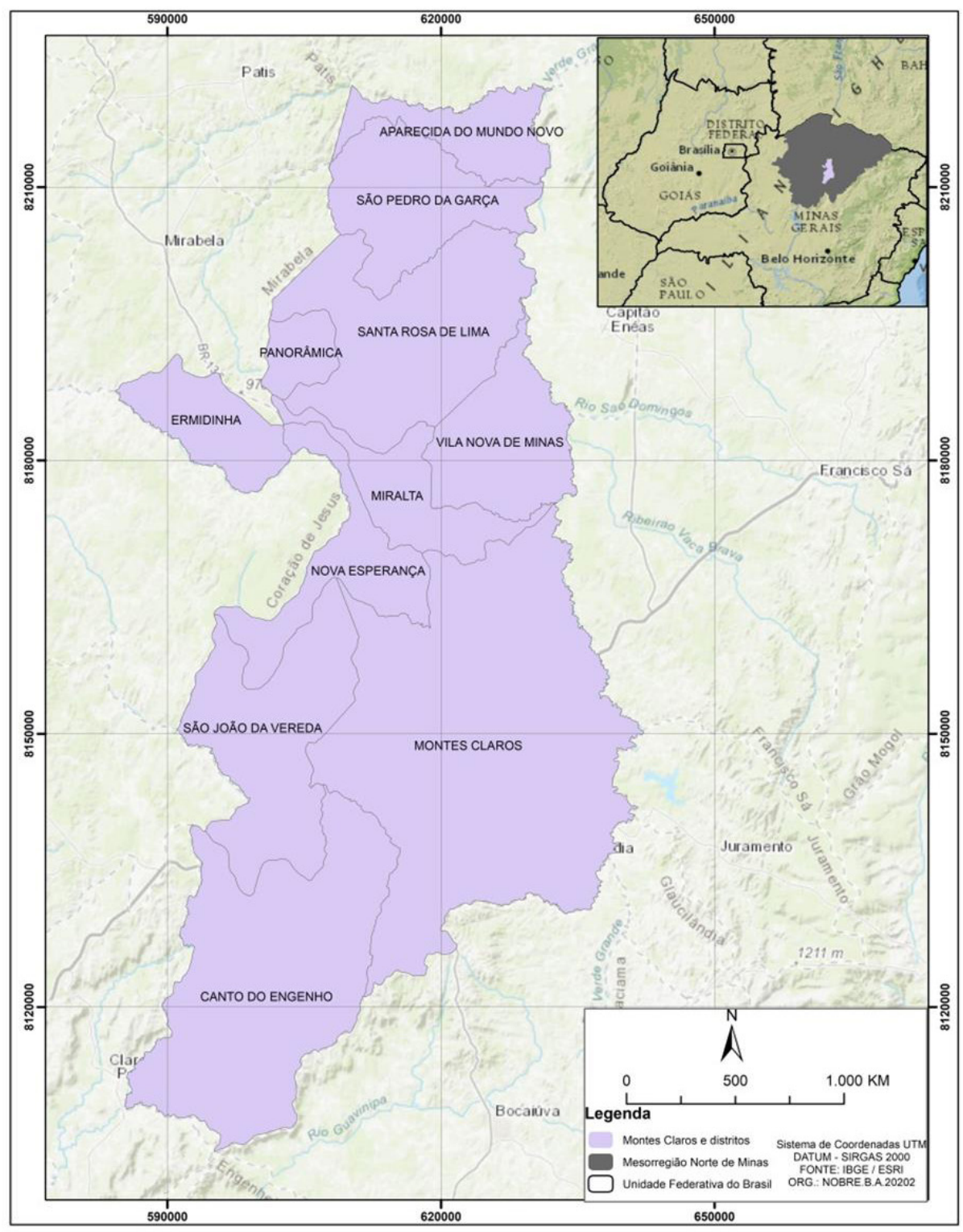

Figura 1 - Mapa de localização da área de estudo.

\section{Procedimentos Operacionais}

O fluxograma (Figura 2) demonstra as etapas executadas para construção da pesquisa. A primeira etapa constitui-se da aquisição das imagens de satélite. As imagens 
são provenientes do período seco, mais precisamente do mês de junho, no qual não há presença de nuvens que interfiram na qualidade da imagem.

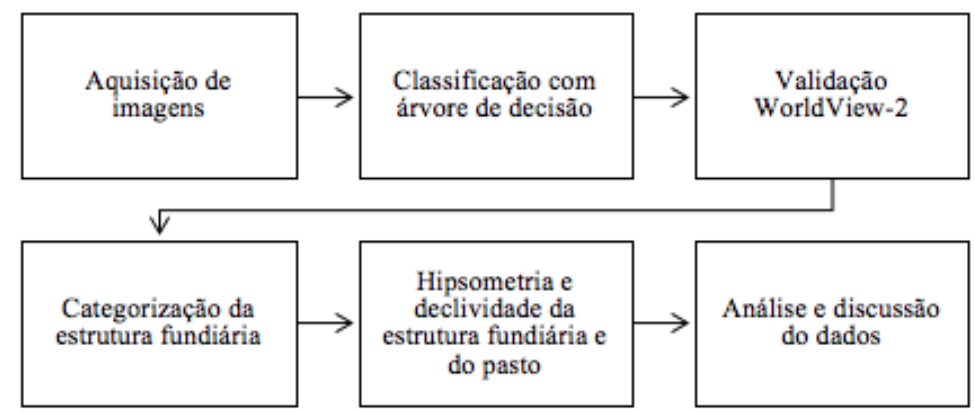

Figura 2 - Fluxograma dos procedimentos técnicos da pesquisa.

Ainda na primeira etapa, para a identificação da pastagem foram utilizadas as cenas T23KPB, T23KNB, T23LNC, T23LPC, provenientes do satélite Sentinel, do ano de 2014 (Tabela 1).

Tabela 1 - Características do Sentinel.

\begin{tabular}{c|c|l|c}
\hline Resolução & $\begin{array}{c}\text { No da } \\
\text { Banda }\end{array}$ & Nome da Banda & $\begin{array}{c}\text { Comprimento de onda } \\
\text { central (nanômetro) }\end{array}$ \\
\hline $10 \mathrm{~m}$ & B02 & Blue (Azul) & 490 \\
\hline $10 \mathrm{~m}$ & B03 & Green (Verde) & 560 \\
\hline $10 \mathrm{~m}$ & B04 & Red (Vermelho) & 665 \\
\hline $10 \mathrm{~m}$ & B08 & NIR (Infravermelho Próximo) & 842 \\
\hline
\end{tabular}

Fonte: Engesat.

Na segunda etapa, a cena foi submetida à classificação automática, usando a árvore de decisão no software ENVI. Árvore de decisão pode ser entendida como uma abordagem flexível, que permite que diferentes características e regras de classificação sejam usadas na separação de diversas classes (SCHOWENGERDT, 1983).

A classificação na árvore de decisão para a identificação da pastagem teve como parâmetros os Algoritmos, NDVI e IAF. O primeiro considera a ponderação das distâncias entre médias dos níveis digitais de cinzas. O segundo algoritmo analisa as condições da vegetação, e o terceiro, a variável biofísica da vegetação ligada à produção de biomassa do dossel. Ainda de acordo com o fluxograma, na terceira etapa, a classe resultante da etapa anterior foi validada com a imagem WorldView-2 do ano 2014, que possui $50 \mathrm{~cm}$ de resolução espacial. Assim, foi possível refinar a classe obtida no procedimento anterior e, após o tratamento, mensurar a área da pastagem. 
Subsequentemente, na quarta etapa, os dados do CAR foram inseridos no ambiente SIG e categorizados pelo tamanho das propriedades rurais, seguindo o estabelecido pelo Instituto Nacional de Colonização e Reforma Agrária - INCRA, na Normativa no 2/MM, de 06 de maio de 2014, que categoriza os imóveis rurais quanto a seu número de módulos ficais. Cada unidade de medida é expressa em hectares.

Em conta não apenas a metragem, que varia de acordo com cada município, mas considera, também, os seguintes fatores: (1) tipo de exploração predominante no município; (2) renda obtida com a exploração predominante; (3) outras explorações existentes no município que, embora não predominantes, sejam significativas em função da renda ou da área utilizada; (4) conceito de propriedade familiar.

No município de Montes Claros, o INCRA estabeleceu que o módulo fiscal ${ }^{1}$ corresponde a 50 ha. Desta maneira, o minifúndio é a propriedade com área inferior a um módulo fiscal, enquanto a pequena propriedade é o imóvel com área de 50 ha a 200 ha, de um a quatro módulos fiscais. Já a média propriedade tem área entre 200 ha e 750 ha, de quatro até quinze módulos fiscais. A grande propriedade ou latifúndio são os imóveis rurais com áreas superiores a 750 ha ou quinze módulos fiscais.

A partir desta categorização, obteve-se a estrutura fundiária do município de Montes Claros. Em sequência, foram cruzadas as categorias obtidas aos dados de pastagem em ambiente SIG, possibilitando-se a análise da distribuição da pastagem por cada categoria fundiária.

Na quinta etapa, representada pelo fluxograma, foram geradas, através do modelo SRTM de $30 \mathrm{~m}$, a hipsometria e a declividade do terreno, o que possibilitou a análise das declividades da pastagem e das propriedades. Por fim, os dados de pastagem, estrutura fundiária e declividade foram cruzados, permitindo correlacionar a distribuição da pastagem por tipo de relevo e por tipo de propriedade.

\section{Resultados e Discussão}

\section{Distribuição Espacial das Propriedades}

É oportuno mencionar que o CAR é uma base de dados essencial no âmbito do planejamento de políticas públicas, investigação das mudanças sociais, principalmente no contexto da estrutura fundiária rural (SILVA, 2015).

Nesse sentido, pontue-se que Montes Claros possui 6.874 imóveis cadastrados no Cadastro Ambiental Rural (CAR), sendo classificados em minifúndios (84\%), pequenas (13\%), médias (3\%) e grandes propriedades (1\%) (CAR, 2019). A Figura 3 mostra a distribuição de tais propriedades pelos distritos do município de Montes Claros.

Da análise da Figura 3 pode-se inferir que, embora os minifúndios representem um maior número de propriedades, quando comparados à área ocupada no município, essa estrutura apresenta as menores áreas, 10\% da área total do município. 


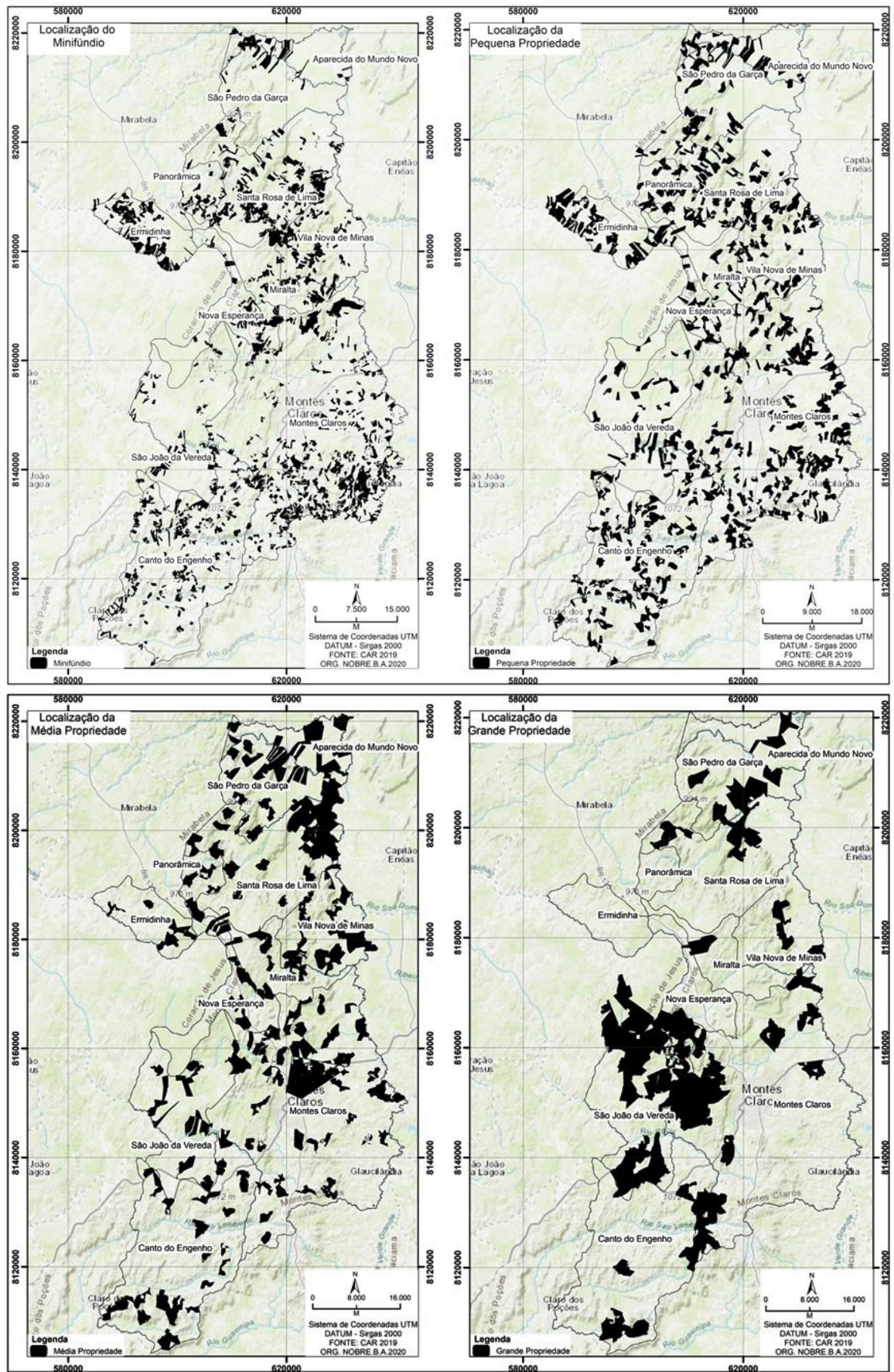

Figura 3 - Estrutura fundiária de Montes Claros. 
A Tabela 2 corrobora tal afirmação, trazendo o número de propriedades por tamanho e os respectivos percentuais que elas ocupam dentro da estrutura fundiária mapeada do município. Conforme os dados da tabela depreende-se que as grandes e médias propriedades, embora em menor número, ocupam as maiores extensões rurais. Dos 217.721,51 ha registrados como imóveis rurais no município de Montes Claros, $58.922,83$ ha (27\% do total) estão divididos entre as grandes propriedades (cerca de 41 imóveis), enquanto $61.961,28$ ha (28\%) estão distribuídos entre as médias propriedades (cerca de 211 imóveis). Consta, ainda, que 59.608,37 ha (27\% da área rural) estão distribuídos entre as pequenas propriedades, perfazendo cerca de 882 imóveis. Já 37.229,03 ha (17\% da área rural) estão distribuídos entre os minifúndios (5.740 imóveis).

Tabela 2 - Percentual da estrutura fundiária.

\begin{tabular}{l|c|c|c}
\hline Tipo de Propriedade & Área (ha) & № Propriedades & $\begin{array}{c}\text { \% de área total em } \\
\text { hectares }\end{array}$ \\
\hline Grande Propriedade & $58.922,83$ & 41 & $25 \%$ \\
\hline Média Propriedade & $61.961,28$ & 211 & $27 \%$ \\
\hline $\begin{array}{l}\text { Pequena } \\
\text { Propriedade }\end{array}$ & $59.608,37$ & 882 & $29 \%$ \\
\hline Minifúndio & $37.229,03$ & 5.740 & $19 \%$ \\
\hline
\end{tabular}

Fonte: CAR (2019).

Da análise do padrão de distribuição destas propriedades pelos distritos do município (Tabela 3), nota-se que, da área total considerada como minifúndio (37.229,06 ha), $33 \%$ encontram-se concentradas no distrito de Montes Claros; enquanto 16\% estão no distrito de Santa Rosa de Lima, 745,42 ha e 2\% estão no distrito Panorâmica.

As pequenas propriedades ocupam 59.608,44 ha e estão distribuídas nos distritos da seguinte forma: $49 \%$ concentram-se no distrito de Montes Claros, $12 \%$ encontram-se no distrito de São João da Vereda, 3\% estão no distrito de Miralta.

As médias propriedades, 61.961,28 ha, concentram-se em 38\% no Distrito de Montes Claros, $15 \%$ no distrito de São João da Vereda e $\%$ no distrito de Panorâmica.

As grandes propriedades, 58.922,83 ha, 27\% concentram-se no distrito de Montes Claros, $16 \%$ no distrito de Nova Esperança e, por fim, 2\% no distrito de Aparecida do Mundo Novo. 
Tabela 3 - Percentual da estrutura fundiária por distrito.

\begin{tabular}{|c|c|c|c|c|}
\hline Distrito & Minifúndio & $\begin{array}{c}\text { Pequena } \\
\text { Propriedade }\end{array}$ & $\begin{array}{c}\text { Média } \\
\text { Propriedade }\end{array}$ & $\begin{array}{c}\text { Grande } \\
\text { Propriedade }\end{array}$ \\
\hline $\begin{array}{l}\text { Aparecida } \\
\text { do Mundo } \\
\text { Novo }\end{array}$ & $\begin{array}{c}3 \% \\
(1.292,46 \text { ha })\end{array}$ & $\begin{array}{c}4 \% \\
(2.566,20 \text { ha })\end{array}$ & $\begin{array}{c}7 \% \\
(3.823,62 \text { ha })\end{array}$ & $\begin{array}{c}2 \% \\
(1.448,20 \text { ha })\end{array}$ \\
\hline $\begin{array}{l}\text { Canto do } \\
\text { Engenho }\end{array}$ & $\begin{array}{c}14 \% \\
(5.335,85 \text { ha })\end{array}$ & $\begin{array}{c}18 \% \\
(10.748,32 \text { ha })\end{array}$ & $\begin{array}{c}12 \% \\
(7.486,46 \text { ha })\end{array}$ & $\begin{array}{c}11 \% \\
(6.644,49 \text { ha })\end{array}$ \\
\hline Ermidinha & $\begin{array}{c}9 \% \\
(3.210,59 \text { ha })\end{array}$ & $\begin{array}{c}7 \% \\
(4.253,42 \text { ha })\end{array}$ & $\begin{array}{c}7 \% \\
(4.231,51 \text { ha })\end{array}$ & $\begin{array}{c}0 \% \\
(0,00 \text { ha })\end{array}$ \\
\hline Miralta & $\begin{array}{c}5 \% \\
(1.960,39 \text { ha })\end{array}$ & $\begin{array}{c}3 \% \\
(1.994,19 \text { ha })\end{array}$ & $\begin{array}{c}18 \% \\
(2.613,84 \text { ha })\end{array}$ & $\begin{array}{c}2 \% \\
(1.183,13 \text { ha })\end{array}$ \\
\hline $\begin{array}{l}\text { Montes } \\
\text { Claros }\end{array}$ & $\begin{array}{c}33 \% \\
(12.294,66 \text { ha })\end{array}$ & $\begin{array}{c}31 \% \\
\text { (18.334,92 ha) }\end{array}$ & $\begin{array}{c}2 \% \\
(1.487,45 \text { ha })\end{array}$ & $\begin{array}{c}27 \% \\
\text { (15.620,69 ha) }\end{array}$ \\
\hline $\begin{array}{l}\text { Nova } \\
\text { Esperança }\end{array}$ & $\begin{array}{c}5 \% \\
(1.727,25 \text { ha })\end{array}$ & $\begin{array}{c}5 \% \\
(2.865,72 \text { ha })\end{array}$ & $\begin{array}{c}5 \% \\
(2.882,73 \text { ha })\end{array}$ & $\begin{array}{c}16 \% \\
(9.142,13 \text { ha })\end{array}$ \\
\hline Panorama & $\begin{array}{c}2 \% \\
(687,77 \text { ha })\end{array}$ & $\begin{array}{c}3 \% \\
(1.506,64 \text { ha })\end{array}$ & $\begin{array}{c}4 \% \\
(2.614,04 \text { ha })\end{array}$ & $\begin{array}{c}0 \% \\
(0,01 \text { ha })\end{array}$ \\
\hline $\begin{array}{l}\text { Santa Rosa } \\
\text { de Lima }\end{array}$ & $\begin{array}{c}16 \% \\
(5.801,21 \text { ha })\end{array}$ & $\begin{array}{c}12 \% \\
(7.167,83 \text { ha })\end{array}$ & $\begin{array}{c}2 \% \\
(1.155,40 \text { ha })\end{array}$ & $\begin{array}{c}7 \% \\
(4.014,61 \text { ha })\end{array}$ \\
\hline $\begin{array}{l}\text { São João da } \\
\text { Vereda }\end{array}$ & $\begin{array}{c}4 \% \\
(1.591,33 \text { ha })\end{array}$ & $\begin{array}{c}6 \% \\
(3.502,78 \text { ha })\end{array}$ & $\begin{array}{c}10 \% \\
(6.333,72 \text { ha })\end{array}$ & $\begin{array}{c}24 \% \\
(14.203,30 \text { ha })\end{array}$ \\
\hline $\begin{array}{l}\text { São Pedro da } \\
\text { Garça }\end{array}$ & $\begin{array}{c}2 \% \\
(758,05 \text { ha })\end{array}$ & $\begin{array}{c}5 \% \\
(2.827,87 \text { ha })\end{array}$ & $\begin{array}{c}6 \% \\
(3.824,64 \text { ha })\end{array}$ & $\begin{array}{c}8 \% \\
(4.585,36 \text { ha })\end{array}$ \\
\hline $\begin{array}{l}\text { Vila Nova de } \\
\text { Minas }\end{array}$ & $\begin{array}{c}7 \% \\
(2.569,48 \text { ha })\end{array}$ & $\begin{array}{c}6 \% \\
(3.840,48 \text { ha })\end{array}$ & $\begin{array}{c}10 \% \\
(6.499,88 \text { ha })\end{array}$ & $\begin{array}{c}4 \% \\
(2.080,91 \text { ha })\end{array}$ \\
\hline TOTAL & $\begin{array}{c}100 \% \\
(37.229,06 \\
\text { ha) }\end{array}$ & $\begin{array}{c}100 \% \\
(59.608,44 \text { ha) }\end{array}$ & $\begin{array}{c}100 \% \\
(61.961,28 \\
\text { ha) }\end{array}$ & $\begin{array}{c}100 \% \\
(58.922,83 \text { ha) }\end{array}$ \\
\hline
\end{tabular}

Fonte: CAR (2019). Org.: Nobre, 2019.

A realidade da estrutura fundiária nacional sofreu poucas modificações no decorrer do tempo, mantendo a concentração de terras. A estrutura fundiária brasileira atual conserva traços da configuração do período colonial, em que grandes extensões de terras 
eram destinadas às classes mais abastadas da coroa portuguesa (MARTINS, 1994). Os dados que representam a estrutura fundiária do município de Montes Claros ilustram bem esta realidade, pois um número pequeno de propriedades (41) concentra grandes extensões de terra enquanto um grande número (5.740) de pequenos estabelecimentos possuem pequenas extensões de terra.

O Município de Montes Claros possui 356.899,27 ha; deste total, 56\% (198.713,52 ha) encontram-se cadastradas no Cadastro Ambienta Rural (CAR). Dos distritos, Nova Esperança é o que possui o maior percentual cadastrado, com 93\% (16.617,82 ha) da estrutura fundiária mapeada. O segundo distrito com maior percentual é Ermidinha, com 85\% $(11.695,52$ ha $)$ da estrutura fundiária mapeada.

O terceiro distrito com maior área mapeada é o de Panorama, com 80\% $(4.808,47)$ da sua área total mapeada. Em seguida, São João da Vereda possui 73\% (25.631,14 ha) da estrutura fundiária mapeada. O quinto distrito com maior percentual é o de Vila Nova de Minas com 70\% (14.990,75 ha). O distrito de Aparecida do Mundo Novo é o sexto com $70 \%(9.130,48$ ha) de sua área total cadastrada. Em oitavo, aparece o distrito de Miralta com 53\% (7.751,55 ha). O distrito subsequente é o de São Pedro da Garça com $50 \%$ de sua área total $(11.995,91$ ha) mapeada.

Os três últimos distritos com os menores percentuais da estrutura fundiária mapeado são os distritos de Canto do Engenho, Montes Claros e Santa Rosa de Lima. O distrito de Canto de Engenho possui cadastrado 49\% (30.215,11 ha) de sua área total. O distrito de Montes Claros possui 44\% (47.737,72 ha) da área cadastrada. O distrito com menor área Cadastrada é o de Santa Rosa de Lima, 43\% (18.139,05 ha) cadastrada.

\section{Distribuição das Propriedades por Classe de Relevo}

Há uma lógica imposta pelo capital na organização da estrutura fundiária, em que as variações hipsométricas e a qualidade do solo interferem no valor da terra, o que, por sua vez, influencia na organização fundiária. Em estudo na Bacia do Rio Vermelho, no centro-oeste de Goiás, as grandes e médias propriedades estão localizadas em áreas relativamente planas, com boas condições de mecanização da produção, enquanto o minifúndio e a pequena propriedade estão localizados em áreas com declividades mais acentuadas, com maiores dificuldades de mecanização e, por conseguinte, com maior custo de produção (SANTOS, 2012).

Em Montes Claros, em que a variação hipsométrica é de 498 m e 1092 m, essa forma de organização também pode ser observada, conforme ilustra a Figura 4.

Conforme a Figura 4, o minifúndio e a pequena propriedade estão localizados em áreas de hipsometria intermediária, entre 511 m e 1080 m. Constatou-se que as médias e grandes propriedades concentram-se em áreas relativamente planas. As médias propriedades estão situadas em áreas com cotas entre 498 m e 1076 m, enquanto a grande propriedade está em áreas com cotas entre 507 m e 1092 m. 


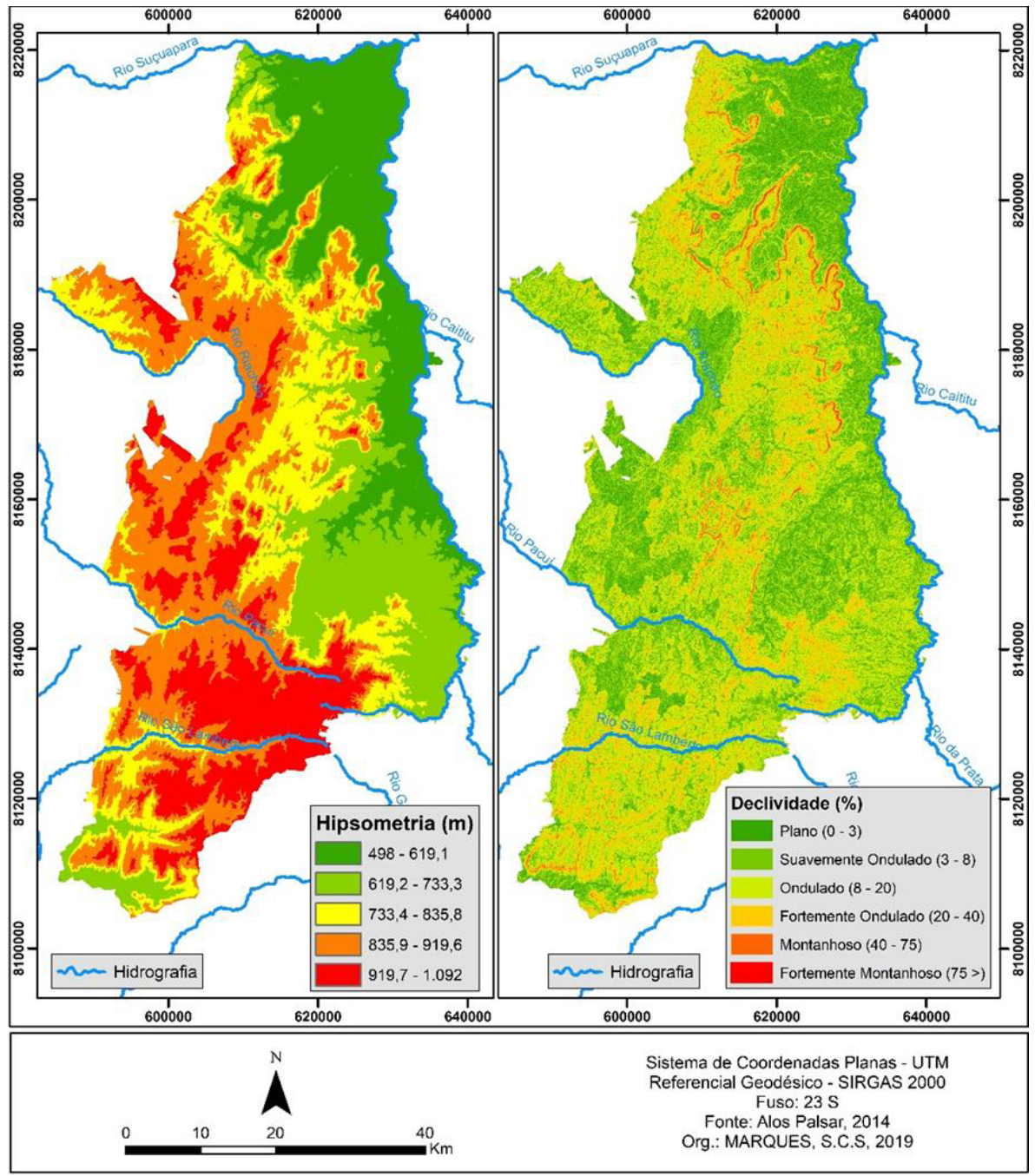

Figura 4 - Hipsometria e declividade de Montes Claros.

A Figura 5 demonstra a declividade das propriedades rurais. Constata-se que as grandes propriedades predominam em áreas de declividade favorável ao desenvolvimento agrícola, enquanto o minifúndio e a pequena propriedade estão situados em áreas de maior declividade, circunstância que é fator de dificuldade para o desenvolvimento das atividades agrícolas nessas áreas.

Ainda, conforme a Figura 5, dos minifúndios, 42\% estão situados em áreas de declividade ondulada e $27 \%$ em áreas de declividade suave ondulada e, ainda, $17 \%$ em áreas de declividade forte ondulada. 


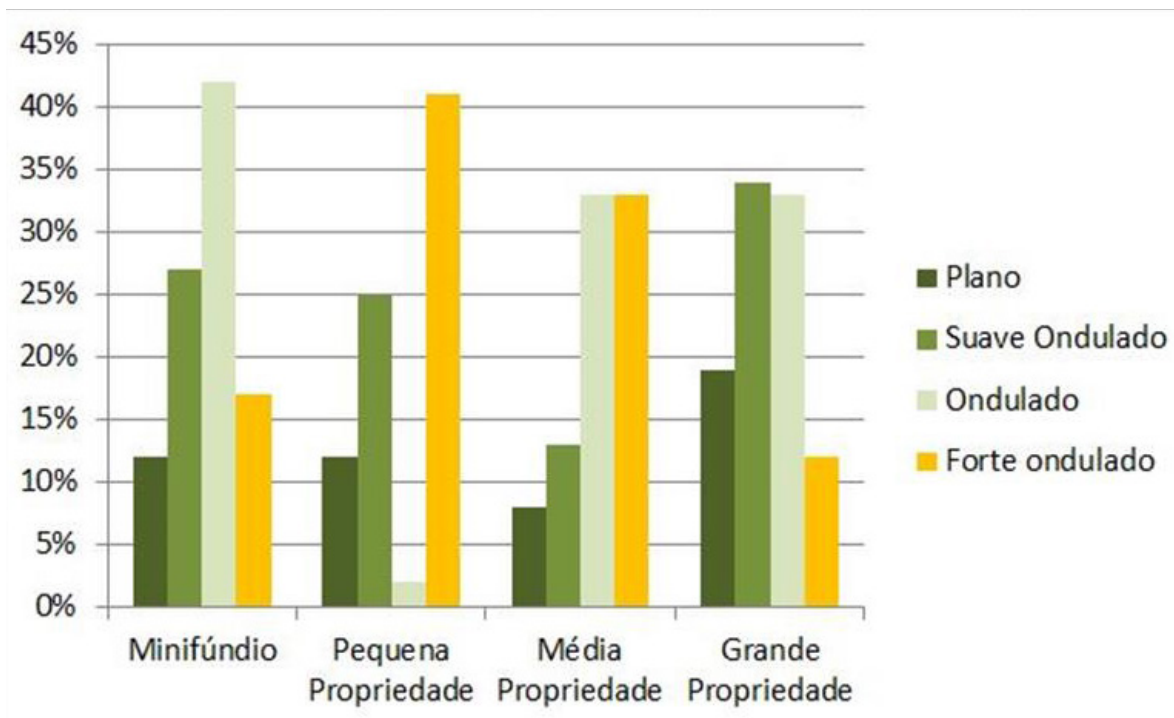

Figura 5 - Tamanho da propriedade por declividade do relevo.

Org.: Nobre, 2020.

Das pequenas propriedades, $41 \%$ estão em áreas de declividade forte ondulada e 25\% (15.036,37 ha) estão em áreas de declividade suave ondulada. Das médias propriedades, 33\% estão em declividade forte ondulada e 32\% em declividade ondulada. Enquanto das grandes propriedades 34\% (20.149,22 ha) estão em áreas de declividade suave ondulada e 33\% (19.253,93 ha) em áreas onduladas e 19\% (11.189,46 ha) estão em áreas planas.

Consoante à Tabela 4, um dos fatores que aumentam o custo da produção agrícola está relacionado às condições apresentadas pela terra para o uso de máquinas, que é definido como "graus de limitação por impedimentos à mecanização" (RAMALHO FILHO e BEEK, 1995).

Tabela 4 - Grau de limitação por impedimentos à mecanização.

\begin{tabular}{l|c|c}
\hline Grau & Declividade & Rendimento Trator (horas) \\
\hline Nulo & $0 \%-3 \%$ & $90 \%>$ \\
\hline Ligeiro & $3 \%-8 \%$ & $75 \%-90 \%$ \\
\hline Moderado & $8 \%-20 \%$ & $50 \%-75 \%$ \\
\hline Forte & $20 \%-45 \%$ & $<50 \%$ \\
\hline Muito Forte & $45 \%>$ & $0 \%$ \\
\hline
\end{tabular}

Fonte: Ramalho Filho e Beek (1995). Org.: Nobre, 2020. 
Na proposta desses autores, infere-se que em Montes Claros o minifúndio e a média propriedade possuem grau de impedimento moderado, haja vista que $42 \%$ e $32 \%$ de suas áreas, respectivamente, estão em terras que não permitem o emprego de máquinas que são comumente utilizadas durante todo o ano. Tais propriedades apresentam relevo moderadamente ondulado a ondulado, com declividade de $8 \%$ a $20 \%$. O rendimento do trator normalmente varia de $50 \%$ a $75 \%$.

A pequena propriedade possui um grau de impedimento forte, pois possui $41 \%$ das terras em áreas - quase sua totalidade -, que necessitam do uso de implementos de tração animal ou máquinas especiais. Caracterizam-se pelos declives acentuados $(20 \%$ a $45 \%$ ), em relevo forte ondulado. O rendimento do trator é inferior a 50\%.

A única estrutura que apresenta boas condições para mecanização é a grande propriedade, que possui grau nulo e ligeiro para a mecanização agrícola. Isso se justifica em razão de 19\% da sua área estar em declividade plana, o que permite, em qualquer época do ano, o emprego de todos os tipos de máquinas e implementos agrícolas ordinariamente utilizados. Essas propriedades são, geralmente, de topografia plana a praticamente plana, com declividade inferior a 3\%, não oferecendo impedimentos relevantes à mecanização. O rendimento do trator é superior a 90\% (RAMALHO FILHO e BEEK, 1995).

A grande propriedade apresenta $34 \%$ da sua área em declividade suave ondulada. Essas terras permitem, também durante quase todo o ano, o emprego da maioria das máquinas agrícolas. Apresentam quase sempre relevo suave ondulado, com declives de 3\% a $8 \%$, no qual rendimento do trator varia de $75 \%$ a $90 \%$ (RAMALHO FILHO e BEEK, 1995).

\section{Considerações Finais}

A estrutura fundiária de Montes Claros foi configurada a partir da formação de grandes propriedades rurais que tinham como principal atividade a criação de gado, introduzido ainda no período colonial devido ao risco que representava às propriedades açucareiras.

Observa-se que a concentração de terras no município de Montes Claros não difere muito das demais localidades do Brasil, prevalecendo a concentração majoritária nas mãos de uma elite numericamente pequena, cenário moldado pela má distribuição histórica da terra e agravado por programas de acesso à renda e à terra, além de legislações temáticas, que acabaram por privilegiar a elite fundiária.

Todo o cenário descrito teve como ferramenta de análise o CAR, que permitiu uma análise da estrutura fundiária do município de Montes Claros e o cruzamento de dados com as informações de pastagem oriundas do processamento digital de imagens. Através da análise dos dados, foi possível concluir que o município de Montes Claros possui um elevado número de propriedades com menos de um módulo fiscal, e que mais de 50\% das áreas destes imóveis são destinados a área de pastagem.

Por fim, tais dados são importantes para embasar políticas públicas, visto a possibilidade de compreender a realidade da estrutura fundiária de Montes Claros e como essa estrutura se apropria da pastagem. 


\section{Referências Bibliográficas}

BRASIL. Programa Mais Ambiente. Decreto Federal no 7.029, de 10 de dezembro de 2009. Brasília, DF, 2009. Disponível em: http://www.planalto.gov.br/ccivil_03/leis/ 17029.htm. Acesso em: mai. 2019.

BRASIL, LEI №; LEI № 4.504, DE 30 DE NOVEMBRO DE 1964. Dispõe sobre o Estatuto da Terra. Disponível em: http: //www.planalto.gov.-br/ccivil_03/leis/l6880.htm, v. 4504, 1964.

CAMACHO, R.S. A histórica concentração fundiária do Brasil: estudo de caso do município de Paulicéia/SP. Geografia em Questão, v. 4, n. 1, p. 43-60, 2011.

CADASTRO AMBIENTAL RURAL (CAR). 2019. Disponível em: https://www.car.gov.br/ publico/imoveis/index. Acesso em: mai. 2019.

IBGE - Instituto Brasileiro de Geografia e Estatística. Cidades. 2010. Disponível em: https:// cidades.ibge.gov.br/brasil/mg/montes-claros/panorama. Acesso em: mai. 2019.

LEITE, M. R. Sensoriamento remoto aplicado à análise temporal da relação uso da terra/ temperatura e albedo de superfície na bacia do Rio Vieira no Norte de Minas Gerais. 2012. 111 f. Dissertação (Mestrado em Ciências Humanas) - Universidade Federal de Uberlândia, 2012. Disponível em: https://repositorio.ufu.br/handle/123456789/16134. Acesso em: jun. 2020.

LOCH, C. A importância da estrutura fundiária no planejamento municipal. Geosul, Florianópolis, v. 3, n. 5, p. 75-84, jan. 1988. ISSN 2177-5230. Disponível em: https://periodicos.ufsc.br/index.php/geosul/article/view/12684/11844. Acesso em: jun. 2020.

MARTINS, José de Souza. O poder do atraso: ensaios de sociologia da história lenta. São Paulo: Hucitec, 1994.

RAMALHO FILHO, A.; BEEK, K. J. Sistema de avaliação da aptidão agrícola das terras. 1995. Rio de Janeiro: EMBRAPA-CNPS, 1995.65p. Disponível em: http://ainfo.cnptia. embrapa.br/digital/bitstream/item/150386/1/sistema-de-avaliacao-agr-terras-3a-edicao1995.pdf. Acesso em: jun. 2020.

SANTOS, R.A.V. Concentração da posse da terra e o Programa Nacional de Crédito Fundiário: uma análise para o Estado do Rio Grande do Norte, 2006-2012. 2012. 141 f. Dissertação (Mestrado em Economia). Universidade Federal do Rio Grande do Norte, 2012.

SCHOWENGERDT, R.A. Techniques for Image Processing and Classifications in Remote Sensing. Academic Press, 1983.P. 247-249. ISBN 9780126289800. Disponível em: http://www. sciencedirect.com/science/article/pii/B9780126289800500147. Acesso em: jun. 2020. 
SILVA, D.F. O Cadastro Ambiental Rural (CAR) como instrumento de informação e monitoramento da reserva legal no estado do Pará. 2015. 109 f. Dissertação (Mestrado em Direito). Centro Universitário do Estado do Pará/Universidade do Estado do Pará, 2015. Disponível em: https://www.cesupa.br/MestradoDireito/dissertacoes/Disserta\%C3\%A7\% C3\%A30\%20-\%20Danielle\%20Fonseca\%20Silva.pdf. Acesso em: jun. 2020.

Recebido em: 08/06/2020 Aceito em: 20/01/2021

\footnotetext{
${ }^{1}$ Lei no 4.504, de 30 de novembro de 1964, denominada Estatuto da Terra, define o módulo fiscal como uma medida de área expressa em hectares, sendo que em cada município o módulo fiscal tem um valor de área em hectares. Essa definição é realizada pelo Instituto Nacional de Colonização e Reforma Agrária (INCRA), levando em consideração fatores como o tipo de exploração predominante no município, a renda obtida no tipo de exploração predominante, entre outros fatores definidos no Estatuto da Terra.
} 